\title{
BILINGUISMO E MULTILINGUISMO: PROCESSAMENTO, APRENDIZAGEM E USO DAS LÍNGUAS
}

\author{
Bernardo Kolling Limberger ${ }^{1}$ \\ Mailce Borges Mota $^{2}$ \\ Augusto Buchweitz ${ }^{3}$
}

O número temático Bilinguismo e multilinguismo reúne estudos empíricos, experimentais e teóricos sobre esse tema complexo e multifacetado. Abordagens diversas advindas da Linguística e de outras áreas do conhecimento (Psicologia, Neurociência, Educação, Sociologia, entre outras) estão envolvidas no entendimento do processamento, aprendizagem e uso de duas ou mais línguas.

A definição e avaliação do bilinguismo tanto quantitativamente como qualitativamente é tão variada quanto as áreas afins. As definições mais atuais do falante bilíngue ou multilíngue valorizam o uso das línguas como parâmetro avaliativo e influenciam o estudo do processamento e da aprendizagem. Grosjean (2010), por exemplo, define bilíngues como aqueles que usam duas ou mais línguas (ou dialetos) no cotidiano. O critério de inclusão no bilinguismo se torna consideravelmente menos conservador ou restritivo quando se parte do princípio do uso das línguas. Dessa forma, aprendizes de uma língua também podem ser considerados e se considerar bilíngues. Além disso, o uso de mais de duas línguas é cada vez mais comum. O termo 'bilinguismo' tem sido mais frequentemente usado para se referir a falantes de duas línguas, ao passo que o termo 'multilinguismo' tem sido mais utilizado para caracterizar falantes de três ou mais línguas (BATHIA; RITCHIE, 2013; KEMP, 2009).

Até pouco tempo, a pesquisa sobre multilinguismo estava integrada na pesquisa sobre bilinguismo. Por exemplo, o Handbook da área, lançado em 2004, incluiu 'multilinguismo' somente em 2013 no seu título (BATHIA; RITCHIE, 2013). Anteriormente, assumia-se, segundo Herdina e Jessner (2002), que os achados sobre bilíngues poderiam ser generalizados para multilíngues. Na última década, o interesse pelo multilinguismo possibilitou a concepção de uma subárea de investigação, com aspectos teóricos e metodológicos específicos (DE BOT; JAENSCH, 2013). Esse ramo de investigação é incipiente e há divergências entre as definições, que derivam da complexa configuração dos falantes com relação à natureza do uso das suas línguas e das diferenças entre backgrounds, ideologias e objetivos dos pesquisadores (KEMP, 2009).

Este número contempla estudos sobre as duas temáticas, abrangendo uma diversidade de perspectivas, populações, métodos e línguas. Os artigos neste número foram divididos em quatro grupos. O primeiro grupo é composto por artigos relacionados a acesso lexical. Esses estudos pretendem se juntar à tradição da pesquisa psicolinguística sobre acesso lexical no multilinguismo, no reconhecimento de palavras desconhecidas e na correlação entre os diversos fatores envolvidos. O segundo grupo também se insere na pesquisa de cunho psicolinguístico e contempla artigos que buscam investigar aspectos relacionados à leitura, considerando a consciência fonológica, o processamento e a compreensão da leitura em língua estrangeira, bem com a dislexia. No terceiro

\footnotetext{
${ }^{1}$ Doutor em Letras/Linguística pela Pontifícia Universidade Católica do Rio Grande do Sul. Professor adjunto da Universidade Federal de Pelotas, Programa de Pós-Graduação em Letras.

${ }^{2}$ Doutora em Letras/Inglês e Literatura Correspondente pela Universidade Federal de Santa Catarina. Professora adjunta da Universidade Federal de Santa Catarina, Programas de Pós-Graduação em Letras/Inglês e Literatura Correspondente e Linguística.

${ }^{3}$ Doutor em Letras/Inglês e Literatura Correspondente pela Universidade Federal de Santa Catarina. Professor associado da Pontifícia Universidade Católica do Rio Grande do Sul, pesquisador do Instituto do Cérebro do Rio Grande do Sul, Escola de Ciências da Saúde e Vida.
} 
grupo, há artigos sobre bilinguismo bimodal, considerando o uso das línguas por uma criança Coda e por surdos, além de histórias linguísticas desse bilinguismo específico. Finalmente, o quarto grupo inclui artigos sobre ensino, aprendizagem e uso de diferentes línguas em contexto formal e informal, focalizando especificidades dos processos e fatores envolvidos.

O número é inaugurado com artigos sobre processamento, mais especificamente, acesso lexical. Aline Duarte e Cintia Blank reportam os resultados do artigo intitulado A influência do priming grafo-fônico-fonológico em uma tarefa de decisão lexical em multilingues falantes de português (L1), inglês (L2) e francês (L3), um estudo psicolinguístico que envolve multilíngues. Os resultados do experimento de priming fornecem evidências adicionais de acesso lexical não seletivo. Segundo essa hipótese, os itens lexicais de todas as línguas faladas pelos indivíduos são ativados simultaneamente, de modo que o acesso a uma palavra de uma língua pode ser influenciado pelo conhecimento das outras línguas conhecidas pelo indivíduo.

A interação entre itens lexicais na mente bilíngue também foi investigada por Pâmela Toassi e Sílvia Pereira. O foco do estudo Understanding Cognate Words in a First Contact with English foi o reconhecimento de palavras cognatas numa língua que não era conhecida pelos participantes. Por meio de uma tarefa de tradução de palavras do inglês para o português, as autoras constataram efeitos do conhecimento do português no reconhecimento de palavras escritas em inglês. Os resultados têm implicações para o ensino de inglês para brasileiros, uma vez que mostram efeitos de facilitação na aprendizagem de vocabulário.

Em Relações entre experiência de leitura, habilidades linguísticas e acesso lexical na L2, Pietra Rigatti e Ana Fontes contribuem para a compreensão de fatores que se relacionam ao acesso lexical em L2, como hábitos de leitura. As autoras aplicaram um questionário sobre leitura e escrita, além de uma tarefa de priming semântico, e evidenciaram relações entre a experiência de leitura em L2, as habilidades autoavaliadas de leitura e escrita e o acesso lexical em L2 de bilíngues português-inglês. Por meio do estudo, pode-se compreender a contribuição da leitura para o aprimoramento do acesso ao léxico e aumento de vocabulário. Este estudo sobre acesso lexical e leitura se relaciona aos estudos do segundo grupo, que contempla investigações psicolinguísticas sobre leitura e bilinguismo.

A leitura é uma tarefa complexa que envolve múltiplas habilidades. É consenso na literatura que habilidades de consciência fonológica são preditoras do desempenho em tarefas de leitura. $\mathrm{O}$ estudo de Ana Belém Nunes e Shasha Wu, Chinese-Portuguese Bilingual's Phonological Awareness: Annotations, contribui para a pesquisa sobre a relação entre leitura e consciência fonológica, considerando bilíngues leitores de duas línguas de sistemas de escrita diferentes. $O$ estudo fornece evidências das maiores dificuldades de chineses nas tarefas de consciência fonológica em português europeu, o que tem implicações tanto para a leitura quanto para o ensino e aprendizagem de português na China, uma demanda cada vez mais crescente.

O foco do próximo artigo publicado é a habilidade de compreensão da leitura de um texto em língua estrangeira, investigada por meio de uma ferramenta altamente precisa para a investigação da leitura. No artigo Processamento de leitura de estudantes universitários em língua alemã como lingua estrangeira, Nair Vansiler e Ângela Klein relatam um estudo que contou com a participação de brasileiros aprendizes de alemão e tem como objetivo verificar a diferença entre dois grupos de aprendizes (níveis A1 e A2) no processamento de leitura. Para tanto, foi aplicado um experimento de leitura de um texto enquanto os movimentos oculares foram rastreados. Os resultados das fixações indicam uso de diferentes estratégias de compreensão do texto e podem contribuir para o aprimoramento de testes de nivelamento e métodos de ensino.

Considerando também a habilidade de compreensão leitora, o artigo Bilíngues e bilinguismos: uma tarefa de leitura e compreensão de texto como alternativa de aferição de proficiência linguística e fluência oral global em língua inglesa, de autoria de Joelton de Santana e Janaina Weissheimer, buscou investigar de que forma uma tarefa de leitura pode ser considerada como critério de 
proficiência linguística. Participantes dos Estados Unidos e do Brasil realizaram um teste de leitura. Os brasileiros também fizeram um teste de proficiência baseado no tamanho do vocabulário. Não houve diferença significativa entre os desempenhos dos participantes agrupados por nível de proficiência no teste de leitura e de vocabulário. $\mathrm{O}$ artigo reforça a necessidade de, em estudos que avaliam bilíngues, ponderar diferentes métodos para caracterizá-los, contribuindo para a visão holística dessa população.

O último artigo da seção sobre leitura aborda uma população com desenvolvimento atípico, ou seja, disléxicos. Trata-se de um tópico que já possui tradição na pesquisa, mas carece de investigações com bilíngues. $\mathrm{O}$ artigo The Impacts of Developmental Dyslexia on the Practice of Second Language Dyslexic Teachers, de Aline Fay e Gabriela Gafforelli, aborda o impacto da dislexia na prática de professores de L2 que são portadores desse transtorno. Por meio de uma revisão da literatura, as autoras refletem sobre características da dislexia, impactos para um professor de L2 e estratégias para os professores lidarem com a própria dislexia. Por fim, as autoras expõem um panfleto baseado na pesquisa, que servirá como um guia de orientações para professores com dislexia.

Investigações sobre populações bilíngues específicas também são o foco do próximo grupo de estudos. O artigo Influência de interlocutores na produção linguística de uma criança Coda durante a aquisição bilíngue e bimodal, redigido por Bianca Gomes e Ronice de Quadros, investiga o uso de Libras e português por uma criança Coda (filho ouvinte de pais surdos) em interação com diferentes interlocutores. Foram analisados vídeos com produções oral-auditivas e gestuais-visuais da criança inserida em diferentes contextos linguísticos. As autoras identificaram influência do interlocutor na produção da criança, em ambas modalidades linguísticas. O estudo mostra a importância da inserção da criança bilíngue bimodal em diferentes contextos para o pleno desenvolvimento do seu bilinguismo.

Também baseado numa visão de uso das línguas Libras e português, o artigo Histórias linguísticas de surdos bilíngues do par Libras-português, apresentado por Giselli Silva, objetiva descrever e analisar o histórico de aquisição da linguagem de surdos e os seus perfis de proficiência sobretudo na Libras. Por meio de um questionário, a autora identificou ampla variação na idade e nos contextos de aquisição da Libras. O estudo tem implicações para a formulação de políticas linguísticas e construção de instrumentos de avaliação objetiva da proficiência em Libras, uma demanda do ensino e da pesquisa.

Os surdos oralizados e não oralizados também foram a amostra investigada no artigo Emprego (e não emprego) de determinantes em textos escritos por surdos. O objetivo do artigo de Dayane de Almeida e Deisieli de Araújo é investigar fatores linguísticos e extralinguísticos que regem a variação no emprego e não emprego de determinantes (por exemplo, artigos, pronomes e numerais) em português. Para tanto, foram analisadas redações de surdos à luz da sociolinguística variacionista e de influências translinguísticas. Os resultados indicam variação sistemática no emprego e não emprego de determinantes, motivada por fatores como a idade de aquisição da Libras, a escolaridade e características linguísticas, como traços semânticos e número. $\mathrm{O}$ estudo pode ter implicações para o ensino de português como L2 para surdos.

O uso, a aprendizagem e o ensino de segunda língua, língua estrangeira e língua adicional, termos que coexistem na literatura, são o foco do último bloco de artigos. O grupo também contempla estudos com falantes de língua de herança. Dessa forma, os artigos abrangem diferentes áreas de estudo e perspectivas; por isso, há variação no uso dos termos e métodos. $\mathrm{O}$ artigo que inaugura o grupo, Portuguese Grammar Instruction: Views of Heritage and Foreign Language Learners, apresentado por Glaucia Silva, compara visões de aprendizes de português como língua de herança e língua estrangeira sobre o ensino de gramática em aulas nos Estados Unidos. Investigada por meio de um questionário, a preferência dos falantes de português como língua de herança foi pela instrução gramatical contextualizada. A instrução gramatical formal, tal como ocorre em aula de 
língua estrangeira, não foi tão útil. Porém, ambos os grupos de aprendizes valorizaram a instrução gramatical explícita. A autora salienta a importância de oferecer abordagens de ensino de língua especializadas a cada um dos grupos.

O seguinte artigo publicado também envolve uma língua de herança. No artigo, Fatores (in)conscientes que influenciaram uma italo-brasileira a usar progressivamente o português em detrimento da variedade italiana, Cristiane Horst, Marcelo Krug e Simone Bernieri têm como objetivo compreender fatores que levaram uma senhora de 90 anos, falante de Talian, variedade linguística ítalo-brasileira, a usar mais português do que a sua língua materna na região oeste de Santa Catarina. Os resultados da entrevista estruturada mostram diversos fatores históricos, políticos, educacionais, culturais, familiares e psicológicos que influencia(ra)m o seu bilinguismo. $\mathrm{O}$ estudo discute pressões sofridas por falantes de línguas minoritárias sobre o uso das línguas e pode contribuir para discussões sobre a manutenção de línguas minoritárias no Brasil.

Outro fator que também influencia o uso e a aprendizagem de determinada língua é um estado psicológico cada vez mais frequente no mundo, a ansiedade. No artigo intitulado Age and Proficiency in Foreign Language Anxiety, Rafael Dutra e Ingrid Finger relatam um estudo cujo objetivo é investigar como proficiência em inglês e idade estão relacionadas à ansiedade em língua estrangeira. Aprendizes de inglês de diversos níveis de proficiência responderam a um questionário de histórico de aquisição da linguagem e a uma escala de ansiedade. Os resultados indicam relação entre proficiência e ansiedade, ou seja, quanto maior o nível de ansiedade, menor o nível de proficiência. Houve relação também com a idade: quanto maior a idade dos participantes, maior foi o seu nível de ansiedade. Os autores salientam a importância de considerar as emoções no ensino de língua estrangeira.

O ensino de inglês também é o foco do artigo An Instrument for English Medium Instruction (EMI) Classroom Observation in Higher Education, apresentado por Ron Martinez, Francisco Fogaça e Eduardo de Figueiredo. O estudo tem como objetivo descrever o desenvolvimento e a validação de um instrumento de observação de aula de inglês como meio de instrução no ensino superior. $\mathrm{O}$ protocolo de observação analisado no artigo foi construído com base na literatura, incorporando alguns aspectos de outros protocolos. Os resultados dos estudos piloto sugerem um protocolo que pode servir para avaliar diferentes interações na sala de aula e diferentes contextos, não se limitando à EMI. O estudo pode contribuir para a discussão da internacionalização do ensino superior no Brasil, por meio da avaliação de aulas de conteúdo ministradas em inglês.

Da mesma forma, Vanessa Matiola aborda a aprendizagem de línguas estrangeiras. No artigo Mediação, colaboração e reflexão compartilhada em teletandem: apontamentos sobre os diferentes tipos de mediação no teletandem da UNESP/FCLAr, especificamente, a autora relata e analisa o papel da mediação no projeto internacional Teletandem, uma modalidade de uso de línguas com tecnologias digitais. As sessões de mediação são feitas na UNESP de Araraquara por meio de diários reflexivos e rodas de conversa. Com essas sessões, notaram-se mudanças na maneira como os participantes relatam suas experiências na língua estrangeira e como pensam sobre elas. $\mathrm{O}$ estudo traz reflexões que fomentam a discussão sobre ensino de línguas com tecnologia e feedback.

No artigo Desafios da sustentabilidade do ensino de português língua mundial nos EUA: projeto vídeo como estratégia intercultural, Renato Alvim e Silvia Ramos-Sollai relatam e analisam um projeto de língua estrangeira (português nos EUA) que envolve outro recurso, o vídeo. O objetivo do estudo é analisar a comunicação intercultural em ambiente instrucional universitário de português nos EUA. Para tanto, os autores aplicaram, no fim do curso introdutório semestral, a interessante tarefa de produção de um vídeo, no qual os alunos falaram apenas português. Além de a tarefa oportunizar aperfeiçoamento linguístico, houve debates acadêmicos que ampliaram a comunicação interpessoal e a competência intercultural. Os resultados sugerem que os aprendizes construíram significado e interação. $O$ trabalho tem implicações sobretudo para a discussão sobre competência intercultural e português pluricêntrico. 
O artigo que encerra o grupo sobre uso e aprendizagem de línguas não maternas é um estudo sociolinguístico conduzido por Débora Aires e Isabella Mozzillo, cujo objetivo é propor reflexões acerca de ideologias linguísticas que têm efeito sobre a aprendizagem de espanhol como língua estrangeira. No artigo intitulado Pureza linguística $x$ alternância raciocinada de línguas: ideologias linguísticas sobre o ensino de língua estrangeira, as autoras identificaram várias visões sobre o contato de línguas, a presença, a função e o uso de português nas aulas de espanhol. As visões dos professores sobre a proximidade e a alternância entre as línguas na sala de aula não são consensuais entre o grupo avaliado. As reflexões fornecem contribuições para o ensino de espanhol para brasileiros, pois ideologias podem influenciar a prática docente e perpetuar ou desmistificar preconceitos.

Por fim, a entrevista com o professor Göz Kaufmann, concedida a Rafael Vetromille-Castro, Bernardo Limberger e Helena Kieling, apresenta opiniões e estudos do entrevistado sobre línguas minoritárias, diversidade linguística, atitudes e crenças sobre línguas. A entrevista Minority Groups and Language Diversity in Germany and Brazil: An Interview with Göz Kaufmann possibilita reflexões importantes sobre a manutenção de línguas minoritárias e achados científicos que dão visibilidade a particularidades de línguas minoritárias e variedades linguísticas, especialmente do Brasil e da Alemanha. Os insights do professor Göz podem fomentar reflexões para a formação de professores e o desenvolvimento de políticas linguísticas.

Esperamos que a seleção de textos deste número da Revista Caderno de Letras demonstre a diversidade de tópicos, áreas, abordagens e métodos do estudo do bilinguismo e multilinguismo. Além disso, desejamos que o número consiga instigar pesquisadores inseridos em diferentes níveis e áreas a aprofundar seus estudos e encontrar novos colaboradores para dialogar. Agradecemos aos autores pelas interessantes contribuições, aos pareceristas pela avaliação e aos leitores pelo interesse. Desejamos leituras repletas de aprendizados a todos!

\section{Referências}

BATHIA, T. K.; RITCHIE, W. C. The Handbook of Bilingualism and Multilingualism. 2. ed. Oxford: Blackwell Publishing Ltd, 2013.

DE BOT, K.; JAENSCH, C. What is special about L3 processing? Bilingualism: Language and Cognition, v. 18, n. 2, p. 130-144, 2013.

GROSJEAN, F. Bilingual: life and reality. Cambridge: Harvard Univ., 2010.

HERDINA, P.; JESSNER, U. A Dynamic Model of Multilingualism: Perspectives of Change in Psycholinguistics. Clevedon/Buffalo/Toronto/Sydney: Multilingual Matters, 2002.

KEMP, C. Defining multilingualism. In: ARONIN, L.; HUFEISEN, B. (Eds.). The Exploration of Multilingualism. Amsterdam/Philadelphia: John Benjamins Publishing Company, 2009. p. 11-26. 